\title{
Confining euchromatin/heterochromatin territory: jumonji crosses the line
}

\author{
Hisashi Tamaru ${ }^{1}$ \\ Gregor Mendel Institute of Molecular Plant Biology, Austrian Academy of Sciences, 1030 Vienna, Austria
}

\begin{abstract}
Heterochromatin is typically highly condensed, gene-poor, and transcriptionally silent, whereas euchromatin is less condensed, gene-rich, and more accessible to transcription. Besides acting as a graveyard for selfish mobile DNA repeats, heterochromatin contributes to important biological functions, such as chromosome segregation during cell division. Multiple features of heterochromatin-including the presence or absence of specific histone modifications, DNA methylation, and small RNAs—have been implicated in distinguishing heterochromatin from euchromatin in various organisms. Cells malfunction if the genome fails to restrict repressive chromatin marks within heterochromatin domains. How euchromatin and heterochromatin territories are confined remains poorly understood. Recent studies from the fission yeast Schizosaccharomyces pombe, the flowering plant Arabidopsis thaliana, and the filamentous fungus Neurospora crassa have revealed a new role for Jumonji $\mathrm{C}(\mathrm{JmjC})$ domain-containing proteins in protecting euchromatin from heterochromatin marks.
\end{abstract}

The nucleosome is the basic unit of a eukaryotic chromosome, consisting of 146 base pairs (bp) of DNA coiled around a core consisting of a histone octamer (Luger et al. 1997). Chromosomes have two structurally and functionally distinguishable territories: euchromatin and heterochromatin. Heterochromatin is highly condensed, genepoor, and transcriptionally silent, whereas euchromatin is less condensed, gene-rich, and more easily transcribed (Huisinga et al. 2006). Nucleosome modifications distinguish heterochromatin from euchromatin. Euchromatin is typically enriched in acetylated histones $\mathrm{H} 3$ and $\mathrm{H} 4$ and H3K4 methylation (H3K4me) (Grunstein 1998; Litt et al. 2001; Noma et al. 2001), whereas heterochromatin is characterized by hypoacetylation of histones, H3K9me (Tschiersch et al. 1994; Rea et al. 2000; Jenuwein and Allis 2001; Nakayam et al. 2001; Schotta et al. 2002), association of heterochromatin protein-1 (HP1) (Eissenberg et al. 1990; Bannister et al. 2001; Lachner et al. 2001; Lachner and Jenuwein 2002), and DNA cytosine methylation $(5 \mathrm{mC})$ in organisms showing this modification (Keshet et al. 1986; Buschhausen et al. 1987; Hennig 1999;

[Keywords: JmjC; 5mC; H3K9me; euchromatin/heterochromatin; transcription]

${ }^{1}$ Correspondence.

E-MAIL hisashi.tamaru@gmi.oeaw.ac.at; FAX 43-1-790449001.

Article is online at http://www.genesdev.org/cgi/doi/10.1101/gad.1941010.
Richards and Elgin 2002; Suzuki and Bird 2008). Pericentromeric and telomeric regions that contain a high density of repetitive DNA elements, such as clusters of satellite sequences and transposons, are the main targets for heterochromatin formation (Martens et al. 2005; Schueler and Sullivan 2006; Blasco 2007; Slotkin and Martienssen 2007; Schoeftner and Blasco 2009). Centromeric heterochromatin is required for correct chromosome segregation (Peters et al. 2001; Lippman and Martienssen 2004; Kanellopoulou et al. 2005; Pidoux and Allshire 2005; Folco et al. 2008). A defining feature of heterochromatin is that it self-perpetuates its transcriptionally repressed state and highly condensed structure on chromosomes in a region-specific manner throughout the cell cycle over generations.

Two pathways for initiating heterochromatin formation are known. The first is an RNAi-based self-enforcing loop mechanism that targets $\mathrm{H} 3 \mathrm{~K} 9$ me by histone methyltransferases (HMTs) to repetitive DNA elements using siRNAs that are complementary to the target (Hall et al. 2002; Volpe et al. 2002; Verdel et al. 2004). In Schizosaccharomyces pombe, the RITS (RNA-induced transcriptional silencing) complex, composed of a chromodomain protein (Chp1), Argonaute (Ago1), and Tas3, together with siRNAs, cooperates with RNA-dependent RNA polymerase (Rdp1) and other factors such as Dicer (Dcr1) to process repeat transcripts into siRNAs (Motamedi et al. 2004; Noma et al. 2004; Verdel et al. 2004; Sugiyama et al. 2005). RNAi-mediated heterochromatin targeting is found in many eukaryotic systems, including fission yeast, animals, and plants. In addition, ties have been found between RNAi and DNA methylation. In mammals and plants, dsRNAs can direct DNA methylation of its homologous sequences (Wassenegger et al. 1994; Wassenegger 2000; Morris et al. 2004; Bayne and Allshire 2005; Matzke and Birchler 2005; Law and Jacobsen 2010). The second pathway is DNA-based and relies on sequence-specific DNAbinding proteins to deliver HMT activity to specific genomic locations. For example, the transcription factors Atf1 and Pcr1 cooperate with Clr3 histone deacetylase (HDAC) to nucleate H3K9me at heterochromatic loci of S. pombe (Jia et al. 2004a; Yamada et al. 2005).

The RNAi-directed targeting of $\mathrm{H} 3 \mathrm{~K} 9 \mathrm{me}$ to a specific heterochromatin nucleation site triggers a self-reinforcing cycle of chain reactions between nucleosome modifications and binding proteins. In most eukaryotes, the chromodomain of HP1 binds to the H3K9me mark and recruits 
additional nucleosome-modifying enzymes, leading to the propagation of HP1-containing heterochromatin (Grewal and Jia 2007). Importantly, heterochromatin assembled at a specific nucleation site can spread along the chromatin fiber through direct or indirect interactions between nucleosome-modifying enzymes and structural heterochromatin proteins such as HP1 (Eissenberg and Reuter 2009). The spread of heterochromatin formation frequently causes position-effect variegation (PEV), the metastable and heritable silencing of a euchromatic gene (Baker 1968; Eissenberg 1989; Henikoff 1990; Schotta et al. 2003; Talbert and Henikoff 2006), which could have a detrimental effect on normal cell functions. Therefore, cells have evolved mechanisms to limit inappropriate infiltration of heterochromatin into euchromatin. Specific DNA barrier (or insulator) elements that function to protect genes against silencing effects of adjacent heterochromatin have been identified in several organisms. For instance, the transcription factor USF1 binds within the insulator element at the $5^{\prime}$ end of the chicken $\beta$-globin locus flanked by condensed chromatin, and recruits euchromatin-promoting enzymatic activities such as histone acetyltransferases (HATs), H3K4, and H4R3 HMTs, thereby counteracting the propagation of heterochromatin (Gaszner and Felsenfeld 2006; S Huang et al. 2007). In $S$. pombe, DNA boundary elements flank heterochromatin domains at the mating type locus and centromeres (Noma et al. 2001, 2006; Thon et al. 2002) and block the spreading of heterochromatin and associated factors, including the RITS complex and the HDAC complex SHREC containing Clr3 (Jia et al. 2004b; Noma et al. 2004; Yamada et al. 2005; Sugiyama et al. 2007). In Drosophila, which does not show fixed DNA barriers, the boundary between heterochromatin and euchromatin is thought to be determined by the local balance between the strength of activities that promote either heterochromatin or euchromatin (Sun et al. 2004; Gaszner and Felsenfeld 2006).

The filamentous fungus Neurospora crassa shows all of the key features of heterochromatin in higher eukaryotes, including $\mathrm{H} 3 \mathrm{~K} 9 \mathrm{me}, \mathrm{HP} 1$, and $5 \mathrm{mC}$, and serves as an outstanding model to elucidate the mechanisms of DNA methylation and heterochromatin formation in eukaryotes (Selker 2004). The genome of Neurospora has evolved an astonishingly radical genetic process, called repeatinduced point mutation (RIP), to defend itself against mobile repeat elements, perhaps at the cost of its own evolution (Selker 1990; Galagan and Selker 2004). Unlike the situation in fission yeast, plants, and animals in which heterochromatin assembly and silencing require processing of its own transcripts into siRNAs, $N$. crassa does not appear to take advantage of RNAi machinery to initiate heterochromatin formation, even though this organism possesses all of the major RNAi components (Chicas et al. 2004, 2005; Freitag et al. 2004b). N. crassa mutants defective in either both dicers (Dcr), all three RdRPs, or both Argonautes (Ago) proteins show normal distribution of $\mathrm{H} 3 \mathrm{~K} 9 \mathrm{me} 3, \mathrm{HP} 1$, and $5 \mathrm{mC}$ in the genome (Freitag et al. 2004b; Lewis et al. 2009). Whether transcription itself plays a role in heterochromatin formation in N. crassa has yet to be addressed. At least in N. crassa, siRNA-directed post-transcriptional gene silencing (PTGS), called quelling (Cogoni et al. 1996; Cogoni and Macino 1999a,b; Cogoni 2001), and transcriptional gene silencing through DNA methylation are independent genome defense systems.

This review highlights a recent Genes \& Development paper from the Selker laboratory (Honda et al. 2010) implicating a Jumonji C (JmjC) domain protein, DNA methylation modulator-1 (DMM-1), in confining euchromatin/heterochromatin domains in N. crassa. Comparisons are made with two other JmjC domain proteins, Epe1 and INCREASE IN BONSAI METHYLATION1 (IBM1), from $S$. pombe and Arabidopsis thaliana, respectively.

\section{The DMM-1 JmjC domain protein in the filamentous fungus $N$. crassa}

\section{RIP generates signals for heterochromatin formation in N. crassa}

Heterochromatin formation in $N$. crassa involves efficient targeting of $\mathrm{H} 3 \mathrm{~K} 9 \mathrm{me} 3, \mathrm{HP} 1$, and $5 \mathrm{mC}$ to chromosome regions containing RIP-mutated (RIP'd) DNA, including centromeres, telomeres, and transposon relics (Selker et al. 2003; Lewis et al. 2009). RIP detects duplicated DNA fragments-regardless of their transcriptional state or foreign or native source-in a pairwise manner, and mutates them with numerous $\mathrm{G}: \mathrm{C}$ to $\mathrm{A}: \mathrm{T}$ transition mutations in the sexual phase of the life cycle /Cambareri et al. 1989; Selker 1990). RIP preferentially mutates CpA to TpA dinucleotides (Singer et al. 1995). As a consequence, RIP'd DNA sequences are both TpA- and A:T-rich. Hence, analyses of the "RIP product index" (TpA/ApT) and the "RIP substrate index" (CpA + TpG/ApC + GpT) can identify sequences that have undergone RIP in the Neurospora genome (Margolin et al. 1998; Selker et al. 2003). Consistent with the hypothesis that RIP serves to control selfish DNA, such as mobile elements, analyses of the sequences of the $N$. crassa genome revealed a complete absence of intact mobile elements (Galagan et al. 2003; Galagan and Selker 2004). On the other hand, because RIP is unable to distinguish between duplications of its own and parasitic foreign DNA, RIP has undoubtedly impacted the evolution of the Neurospora genome, since gene duplications are considered to be important for the evolution of new gene/protein functions and regulation (Galagan and Selker 2004). As an obvious consequence of RIP, the Neurospora genome has only a few highly similar duplicate genes. Most, if not all, N. crassa paralogs duplicated and diverged before RIP evolved (Galagan et al. 2003).

RIP'd DNA fragments typically function as portable de novo DNA methylation "signals"; i.e., when introduced in an unmethylated single-copy form into the genome by transformation, they trigger methylation of themselves and nearby sequences in all sequence contexts-CG, CHG, and CHH-in vegetative cells (Selker et al. 1993), and can potentially inhibit transcription elongation (Rountree and Selker 1997). As is typical of heterochromatin, RIP'd chromatin enriched in H3K9me, HP1, and $5 \mathrm{mC}$ can cause transcriptional silencing of associated genes (Selker et al. 1993; Cambareri et al. 1996; Irelan and 
Selker 1997). Profiling the distribution of H3K9me3, HP1, and $5 \mathrm{mC}$ across an entire chromosome (LGVII) of wildtype $N$. crassa strains by chromatin immunoprecipitation (ChIP)-chip demonstrated that H3K9me3, HP1, and 5mC colocalize extensively to form discrete heterochromatin domains in naturally RIP'd DNA sequences (Lewis et al. 2009). In contrast to the situation in animals and plants, coding sequences and virtually all promoters of genes were free of $\mathrm{H} 3 \mathrm{~K} 9 \mathrm{me} 3, \mathrm{HP} 1$, and $5 \mathrm{mC}$.

To examine the extent to which methylation of $\mathrm{H} 3 \mathrm{~K} 9$ and DNA depend on de novo or pre-existing methylation at naturally occurring RIP'd heterochromatic regions in the Neurospora genome, Selker and colleagues (Lewis et al. 2009) crossed dim-5 and dim-8 strains, both of which show complete loss of $\mathrm{H} 3 \mathrm{~K} 9 \mathrm{me} 3$ and $5 \mathrm{mC}$; isolated a $\mathrm{dim}^{+}$recombinant; and tested which genomic regions were subjected to de novo methylation of $\mathrm{H} 3 \mathrm{~K} 9 \mathrm{me} 3$ and DNA. Strikingly, H3K9me3 and DNA methylation were restored with $100 \%$ fidelity at all of the heterochromatic regions. This demonstrates that $\mathrm{H} 3 \mathrm{~K} 9 \mathrm{me} 3$ and DNA methylation are efficiently established de novo and maintained, and that they do not depend on preexisting methylation of H3K9 or DNA.

\section{Interrelationship between H3K9me, HP1, and DNA methylation at heterochromatin in N. crassa}

Null mutations in either DIM-5 or HPO, which encode a H3K9 HMT (Tamaru and Selker 2001) and a HP1 (Freitag et al. 2004a), respectively, eliminate all detectable DNA methylation, as does mutation of the DNA methyltransferase (DMT) gene dim-2 (Foss et al. 1993; Kouzminova and Selker 2001). DIM-5 specifically trimethylates H3K9, and trimethyl-H3K9 (H3K9me3) is associated specifically with methylated DNA (Tamaru et al. 2003). A role of H3K9me in the control of DNA methylation has been found also in plants and animals (Jackson et al. 2002; Lehnertz et al. 2003). H3K9me3 provides a binding site for the HP1 chromodomain (Freitag et al. 2004a). HP1 interacts directly with DIM-2, independently of $\mathrm{H} 3 \mathrm{~K} 9 \mathrm{me} 3$, thereby acting as an adapter between methylation of histones and DNA. The interaction between DIM-2 and HP1 involves a pair of PXVXL-related motifs in the $\mathrm{N}$-terminal region of DIM-2 and the chromo shadow domain of HP1, and is essential for DNA methylation (Honda and Selker 2008). The DIM-2/HP1 complex does not include DIM-5. The findings led to the conclusion that DNA methylation in $N$. crassa is a stepwise process in which DIM-5 methylates histone H3K9, and then the DIM-2/HP1 complex recognizes the resulting H3K9me3 mark via the chromo domain of HP1, allowing DIM-2 to methylate nearby nucleosomal DNA. Consistent with this model, genome-wide mapping of H3K9me3, HP1, and $5 \mathrm{mC}$ in dim-5, hpo, and dim-2 mutant strains indicated that DIM-5 is required for HP1 and $5 \mathrm{mC}$ localization, whereas targeting H3K9me3 does not depend on DIM-2 or HPO at the vast majority of heterochromatic regions (Lewis et al. 2009). An unsolved mystery is how RIP'd DNA-containing nucleosomes can be specifically targeted by DIM-5 for the H3K9me3 mark to establish
DNA methylation and subsequent heterochromatization in N. crassa.

Does a DNA-based mechanism target heterochromatin formation in $\mathrm{N}$. crassa?

It is tempting to speculate that heterochromatization in $N$. crassa is initiated by the recognition of features of RIP'd nucleosomal DNA by unidentified DIM-5-associated factor(s). Previous tests of nested sets of DNA fragments from a relic of RIP, the 1.6-kb zeta-eta region, or its mutated versions, for their capacity to induce de novo methylation in single copy at a specific locus revealed multiple positive signals that trigger methylation of its own and flanking non-RIP'd DNA sequences. Neither A:T richness nor a high content of TpA dinucleotides is an essential feature of methylation signals, but both promote de novo methylation (Miao et al. 2000). Thus, the A:T-rich nature of the product of RIP, rather than any specific DNA sequences, appears to be the trigger and the target for heterochromatin formation.

Subsequently, in vivo tests of various simple short synthetic DNA sequences for their potential to trigger de novo methylation of nearby cytosines at a synthetic locus "poised for methylation" revealed features of the methylation signals common with DNA binding by the AT-hook motif found in proteins such as mammalian HMG-1 (Reeves 2001), which binds to the minor groove of A:T base pairs (Tamaru and Selker 2003): (1) G:C base pairs inhibit methylation. (2) Both $\mathrm{T}$ and $\mathrm{A}$ residues are required on a given strand to induce appreciable methylation. (3) DNA lengths shorter than one nucleosomewrapping DNA (146- bp) of the most potent signals can induce de novo methylation in sequences without RIP. (4) Extending signal lengths strengthen methylation. (5) A:T tracts as short as $2 \mathrm{bp}$ are able to cooperate to induce methylation. Consistent with the hypothesis that A:T-hook proteins play a role in signaling DNA methylation, Distamycin A, an analog of the AT-hook motif, suppressed DNA methylation and transcriptional gene silencing in N. crassa (Tamaru and Selker 2003). Finally, a correlation between the strength of methylation signals and their binding to AT-hook proteins in vitro was observed. These collective findings prompted a proposal that de novo DNA methylation in Neurospora is triggered by cooperative recognition of the minor groove of multiple short A:T tracts, presumably by one or more AT-hook proteins that interact with DIM-5 (Tamaru and Selker 2003).

In a recent Genes \& Development paper, Selker and colleagues (Honda et al. 2010) explored this possibility by searching for the A:T-hook proteins that read signals for initiating heterochromatin formation in $N$. crassa.

\section{Identification of DMM-1 and its associated protein, DMM-2}

The $N$. crassa genome has at least 30 genes that encode proteins containing A:T-hook motifs. Honda et al. (2010) first focused on four predicted proteins with two or more A:T-hooks, disrupted the corresponding genes by homologous recombination, and tested DNA methylation. None 
of the null mutations resulted in global methylation defects comparable with those of dim-5, hpo, and dim-2 strains. Interestingly, however, one of them, which Honda et al. (2010) named dmm-1, was found to cause both DNA hypomethylation and, more frequently, hypermethylation at several relics of RIP that are normally methylated in $N$. crassa. The $d m m-1$ gene encodes a protein that contains three A:T-hook motifs, a JmjC domain, and two cysteine-rich regions. Phylogenic analyses of JmjC domains from various species revealed that the JmjC domain of DMM-1 does not have any close homologs in humans, flies, worms, or yeasts. More detailed analysis of DNA methylation in the $d \mathrm{~mm}-1$ mutant strain revealed that the dmm-1-induced DNA hypermethylation resulted from spreading of methylation both upstream of and downstream from the methylated regions. This suggests a role for DMM-1 in confining $5 \mathrm{mC}$ within heterochromatic regions. Complementation tests with a series of DMM-1 constructs with mutated versions of the $\mathrm{JmjC}$ domain, cysteine-rich regions, or A:T-hook motifs in a $\mathrm{dmm}-1 \mathrm{mu}-$ tant indicated that the JmjC domain and two cysteine-rich regions, but not the AT-hook motifs, ironically, are essential for the DMM-1 function.

In vivo copurification and coimmunoprecipitation of DMM-1-associated proteins identified a protein that Honda et al. (2010) named DMM-2. DMM-2 contains a fungal-specific $\mathrm{Zn}(\mathrm{II})_{2} \mathrm{Cys}_{6}$ binuclear cluster DNA-binding domain (MacPherson et al. 2006). In other proteins, this domain binds to simple DNA sequences such as CGG and CCG trinucleotides. Phylogenic analysis of DMM-2 revealed that it is conserved only in the filamentous fungi that possess a DMT DIM-2 homolog. Supporting the idea that DMM-2 collaborates with DMM-1 in modulating DNA methylation, a dmm-2 mutation also caused DNA hypermethylation defects similar to those in dmm-1 mutant strains, but to a lesser extent.

\section{DMM-1 plays a role in preventing heterochromatin from spreading into genes}

Interestingly, whereas $d m m-2$ strains grow nearly normally, dmm-1 strains show severe growth defects. This finding led Honda et al. (2010) to hypothesize that further spreading of DNA methylation across RIP'd transposon relics in $d m m-1$, compared with $d m m-2$, strains might silence neighboring housekeeping genes, resulting in growth inhibition. Consistent with the idea, a null mutation in the dim-2 DMT gene fully rescued the growth defects of $d m m-1$. To further test this hypothesis, Honda et al. (2010) conducted ChIP-chip analysis of LGVII with anti-5mC antibodies on DNA from wild-type, $d m m-1$, and dmm-2 strains. Almost all of the peaks of $5 \mathrm{mC}$ in $d m m-1$ and $d m m-2$ strains colocalized, but close inspection revealed that $d \mathrm{~mm}-2$ strains displayed less extensive spreading of $5 \mathrm{mC}$, and at a smaller number of the regions, compared with $d m m-1$ strains. Strikingly, in $d m m-1$, but not in $d \mathrm{~mm}-2$, strains, DNA methylation spread into 10 genes, and, of these, a putative essential gene encoding a transcription factor, whose expression is reduced in dmm-1 strains, was found. Similar ChIP-chip analysis with anti-H3K9me3 antibodies on chromatin from wildtype and dmm-1 strains demonstrated that H3K9me spreads beyond RIP'd heterochromatic regions, concomitantly with $5 \mathrm{mC}$, in $d \mathrm{~mm}-1$ strains.

To gain insights into the mechanisms by which DMM-1 prevents spreading of $\mathrm{H} 3 \mathrm{~K} 9 \mathrm{me} 3$ and DNA methylation beyond heterochromatic regions, Honda et al. (2010) investigated the distribution of DMM-1 on LGVII in wildtype $N$. crassa strains by ChIP-chip analyses using antibodies against a DMM-1-HA fusion protein. Remarkably, peaks of DMM-1 localization were found to coincide with the edges of RIP'd heterochromatic regions, resembling the localization pattern of HP1 observed previously (Lewis et al. 2009). ChIP analyses using an N. crassa strain expressing DMM-1, DMM-2, and HP1, each tagged with a different epitope, revealed that all three proteins were preferentially localized at the edges of methylated regions. In contrast, $\mathrm{H} 3 \mathrm{~K} 9 \mathrm{me} 3$ was distributed uniformly throughout the regions. Enrichment of DMM-1 and DMM-2 at RIP'd regions was greatly reduced in dim-5 or hpo, but not dim-2, backgrounds, indicating that chromatin binding by the DMM-1/DMM-2 complex depends on the presence of $\mathrm{H} 3 \mathrm{~K} 9 \mathrm{me} 3$ and HP1, but not $5 \mathrm{mC}$. Association of DMM-2 with chromatin depends on DMM-1, as suggested by the loss of DMM-2 enrichment throughout the heterochromatic regions in the $d \mathrm{~mm}-1$ background. Careful biochemical analyses detected a weak interaction between DMM-1 and HP1, which depends on the salt concentration in the extraction buffer. Coimmunoprecipitation assays in various mutant backgrounds revealed that the HP1/DMM-1 interaction is independent of DIM-2, DIM-5, and DMM-2. Collectively, the findings support the idea that HP1 recruits two opposing activities of DIM-2 and DMM-1/DMM-2, which establishes and antagonizes DNA methylation, respectively, to maintain and restrict heterochromatin within RIP'd DNA sequences in $N$. crassa.

\section{A role for DMM-2 in anchoring DMM-1 to the euchromatin/heterochromatin boundary}

Interestingly, a null mutation of $d \mathrm{~mm}-2$ led to the spreading of HP1 and DMM-1 into adjacent non-RIP'd euchromatic sequences. This suggested that DMM-2 is required for docking HP1/DMM-1 at euchromatin/ heterochromatin boundaries, perhaps by binding to DNA near the edges of RIP'd DNA sequences through its $\mathrm{Zn}(\mathrm{II})_{2} \mathrm{Cys}_{6}$ DNA-binding domain. Honda et al. (2010) propose that the HP1/DIM-2 complex binds transiently to $\mathrm{H} 3 \mathrm{~K} 9 \mathrm{me} 3$ at RIP'd chromatin, nucleates and spreads to allow DIM-2 DMT to introduce $5 \mathrm{mC}$ throughout the RIP'd sequences, and then recruits the DMM-1/ DMM-2 complex to stop HP1/DIM-2 at the euchromatin/ heterochromatin borders. In the absence of DMM-1 or DMM-2, HP1/DIM-2 continues to nucleate and spread across the adjacent nucleosomes that do not contain H3K9me3, allowing DIM-2 to methylate the neighboring non-RIP'd DNA sequences. Although it is not clear whether or not a DIM-2/HP1/DMM-1/DMM-2 complex exists, a simpler explanation could be that such a complex 
would progressively methylate $\mathrm{RIP}^{\prime} \mathrm{d}$ regions but stops when it reaches its edges.

How does DMM-1/DMM-2 recognize the

Interestingly, DMM1 has cysteine-rich domains that resemble that of mammalian DNMT3L, which binds to unmethylated H3K4 (Ooi et al. 2007). Given that, as in animals and plants, silent chromatin in $N$. crassa is typically deprived of the H3K4me mark, this observation raised the possibility that DMM-1 binds to unmethylated H3K4 on RIP'd heterochromatin. However, no binding of the DMM-1 cysteine-rich domains to any unmethylated or methylated $\mathrm{H} 3$ and $\mathrm{H} 4$ tails was detectable (Honda et al. 2010). It still remains possible that the binding requires one or more unidentified factors in vivo. Loss of DMM-2 association with RIP'd chromatin in $d m m-1$ strains suggests that the DNA-binding domain of DMM-2 is not sufficient for the association. In the absence of specific DNA boundary elements, recognition of both euchromatic and heterochromatic features would facilitate the preferential localization of the DMM-1/DMM-2 complex to euchromatin/heterochromatin borders. It is interesting to consider that DMM-1/DMM-2 may bind to both RIP'd and non-RIP'd sides of euchromatin/heterochromatin boundaries through the DMM-1 cysteine-rich domains and the DMM-2 $\mathrm{Zn}(\mathrm{II})_{2} \mathrm{Cys}_{6}$ DNA-binding motif, respectively, resulting in a high concentration of the complex at the boundaries (Fig. 1).

Does DNA methylation take the lead when heterochromatin spreads into euchromatin in N. crassa?

Positive feedback loops have been implicated in the propagation of heterochromatin in several eukaryotic systems. For example, in $S$. pombe, the Clr4 H3K9 lysine methyltransferase (KMT) binds to methylated $\mathrm{H} 3 \mathrm{~K} 9$ via its chromodomain, thereby facilitating the spreading of H3K9me beyond RNAi-dependent nucleation sites in cooperation with the methyl H3K9-binding protein Swi6 (homolog of HP1), which also has a chromodomain (Hall et al. 2002; Zhang et al. 2008). Similarly, Drosophila and mammalian SU(VAR)3-9 H3K9 KMTs interact with HP1 (Aagaard et al. 1999; Schotta et al. 2002). In A. thaliana, the chromodomain of the CHROMOMETHYLASE 3 (CMT3) DMT interacts with histone H3 methylated at $\mathrm{K} 9$ and $\mathrm{K} 27$ to target $5 \mathrm{mC}$, and the KRYPTONITE H3K9 KMT binds to $5 \mathrm{mC}$ via its SRA domain to target histone methylation (Lindroth et al. 2004; Johnson et al. 2007). In mammals, H3K9 KMTs interact with DNA methyl-binding domain (MBD) proteins (Fujita et al. 2003; Sarraf and Stancheva 2004). The lack of putative methyl H3K9 binding, methyl DNA binding, and HP1-interacting domains in the DIM-5 KMT suggested limited positive feedback from the HP1/DIM-2 DMT complex in the DNA methylation pathway of $N$. crassa. Consistent with this view, HP1 has only a modest impact on the distribution of H3K9me3 (Lewis et al. 2009). Similarly, while a null mutation in the H3K9 HMT gene dim-5 eliminates all

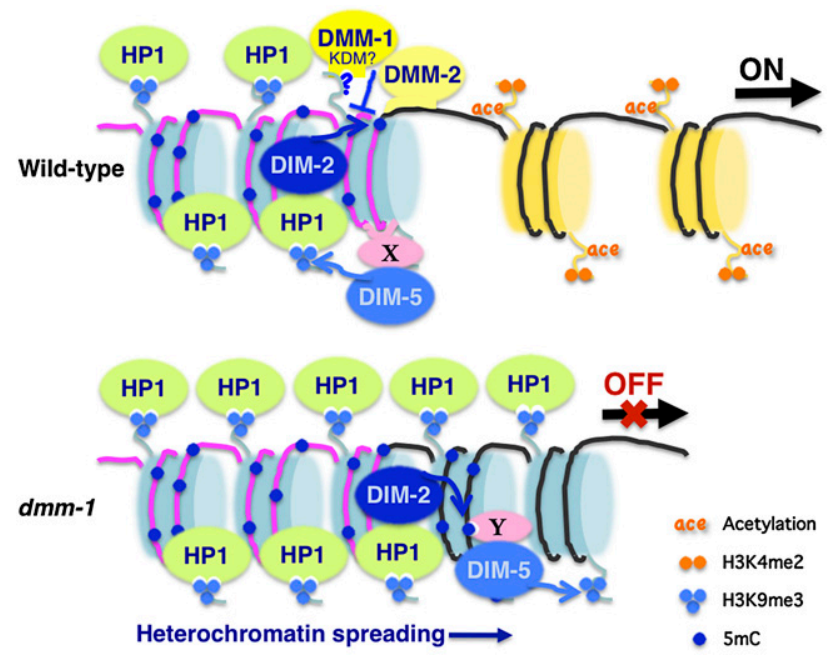

Figure 1. Model for the involvement of DMM-1 in preventing spreading of heterochromatin into euchromatin. In N. crassa, chromatin regions containing A:T-rich DNA sequences (pink fiber) that have been subjected to RIP constitute heterochromatin (nucleosomes in blue). RNAi components are dispensable for heterochromatin targeting. It is thought that an unidentified protein $(\mathrm{X})$ that recognizes TpA/ApT base pairs recruits DIM-5 HMT to establish H3K9me. HP1 forms a complex with the DMT DIM-2 and binds to H3K9me via its chromodomain, allowing DIM-2 to methylate nucleosomal DNA $(5 \mathrm{mC})$ in all sequence contexts. HP1 also recruits DMM-1 and its associated protein, DMM-2, to RIP'd heterochromatic regions. The HP1/ DMM-1/DMM-2 complex is preferentially localized to edges of heterochromatin to block HP1/DIM-2 and/or DIM-5 activity. DMM-1/DMM-2 may bind to both RIP'd and non-RIP'd sites of heterochromatin/euchromatin boundaries through the DMM-1 cysteine-rich domains that are implicated in binding to an unidentified histone mark (question mark) and the DMM-2 $\mathrm{Zn}(\mathrm{II})_{2} \mathrm{Cys}_{6}$ DNA-binding motif, respectively. A dmm-1 mutation allows HP1/DIM-2 to spread across non-RIP'd euchromatic regions (nucleosomes in yellow) and methylate non-RIP'd DNA (black fiber). In this situation, $5 \mathrm{mC}$ attracts DIM-5 to methylate H3K9, presumably via an unidentified DNA methyl-binding protein $(\mathrm{Y})$. Heterochromatin spreading can silence nearby genes. Although the JmjC domain of DMM-1 is required for its function, histone lysine demethylase (KDM) activity has not been detected for DMM-1 (Honda et al. 2010).

known DNA methylation in Neurospora, loss of the DMT gene dim-2 does not influence H3K9me3 and HP1 binding to chromatin at most, if not all, natural relics of RIP (Lewis et al. 2009). This indicates that DNA methylation depends on H3K9me, but not vice versa.

Unexpectedly, ChIP experiments with antibodies against $\mathrm{H} 3 \mathrm{~K} 9 \mathrm{me} 3$ revealed that spreading of methylation beyond some RIP'd heterochromatic regions in $d m m-1$ strains was suppressed by a dim-2-null mutation, suggesting that this ectopic H3K9me depends on DNA methylation. How does this transition in the "methylation leadership" occur? It seems likely that, in the wildtype situation, the DIM-5/X complex (in which $\mathrm{X}$ is a hypothetical RIP'd DNA-binding protein) specifically recognizes RIP'd nucleosomal DNA through X, and DIM5 trimethylates nearby H3K9 (Fig. 1). The HP1/DIM-2 
complex then binds to H3K9me3 via the chromodomain of HP1, and DIM-2 methylates the associated DNA. The HP1/DMM-1/DMM-2 complex enriched at non-RIP'd/ RIP'd euchromatin/heterochromatin boundaries presumably restricts the localization of the HP1/DIM-2 complex and DNA methylation within RIP'd regions. In $d m m-1$ or dmm-2 strains, HP1/DIM-2 and subsequent DNA methylation spread into the adjacent non-RIP'd nucleosomal DNA, and then the DIM-5/Y complex (in which $\mathrm{Y}$ is a hypothetical methyl DNA-binding protein) binds to $5 \mathrm{mC}$ through Y, and DIM-5 trimethylates H3K9 (Fig. 1).

Notably, unlike the situation of natural relics of RIP, experimentally RIP'd DNA fragments, when introduced into the wild-type $N$. crassa genome by transformation, frequently cause spreading of DNA methylation far across non-RIP'd flanking sequences (Miao et al. 2000; Tamaru and Selker 2003). Assuming that DIM-5 HMT loses its control of DNA methylation in non-RIP'd euchromatic sequences, the spreading of DNA methylation over nonRIP'd DNA might direct H3K9me also in the wild-type background. Moreover, there are indications that DNA methylation is required for $\mathrm{H} 3 \mathrm{~K} 9$ me of transcriptionally competent sequences. For example, H3K9me3 is lost in an experimentally RIP'd allele of the $N$. crassa am gene $\left(a m^{R I P 8}\right)$ in a dim-2 DMT mutant (Supplemental Fig. 2; Tamaru et al. 2003). A methyl DNA-binding activity has been identified in $N$. crassa cell extracts (Selker et al. 2002). Thus, it is reasonable to assume that, despite a limited feedback loop, factors that read DNA methylation are required to reinforce the establishment of $\mathrm{H} 3 \mathrm{~K} 9 \mathrm{me} 3$ by DIM-5 HMT under certain conditions also in Neurospora. It would be interesting to investigate how the DMM-1/ DMM-2 complex would work under such conditions.

\section{The Epe1 JmjC domain protein in the fission yeast $S$. pombe}

\section{Epe1 has a role in preventing spreading}

of heterochromatin into euchromatin

The JmjC domain protein Epelwas identified originally in a genetic screen for mutations that promote gene silencing beyond the natural borders of heterochromatin domains in S. pombe (Ayoub et al. 2003). Later, Epel was also identified as a Swi6-interacting protein (Zofall and Grewal 2006; Trewick et al. 2007). Loss of Epel causes spreading of H3K9me deposited by Clr4 HMT and its binder, Swi6, across heterochromatic barriers, otr at centromeres, and $I R-L / R$ at the mating type (mat) locus, resulting in silencing of reporter genes inserted at adjacent euchromatin (Ayoub et al. 2003; Zofall and Grewal 2006). Of note, whereas an epe 1 mutation predominantly causes enhanced silencing in the majority of cells, a smaller population of $\Delta e p e 1$ cells exhibits variegated expression of marker genes located within the heterochromatic regions that are normally silenced (Trewick et al. 2007). Given that loss of Epel causes reduction in siRNAs derived from centromeric repeat transcripts (Trewick et al. 2007), the simplest account for the reverse epe 1 effect is that, in a small population of cells, $\Delta$ epe 1 leads to complete loss of the repeat transcripts, which in turn affects the siRNA production-heterochromatin assembly loop, ultimately resulting in variegated derepression. $\Delta$ epe 1 still results in the formation of extended heterochromatin domains in RNAi pathway mutant backgrounds (e.g., dcr1 and rpb2m203), suggesting that Epel is not a component of the RNAi machinery (Trewick et al. 2007).

\section{Swi6/HP1 recruits Epe1 and Clr3 to balance transcription and silencing of heterochromatin}

The emerging concept of heterochromatin is that it needs to be transcribed to maintain its assembly and silencing (Grewal and Elgin 2007; Kloc and Martienssen 2008). Paradoxically, maintenance of heterochromatin formally requires transcription of the target tandem repeats to generate precursor RNAs (pre-siRNAs) to allow continuous production of siRNAs (Martienssen 2003). Accordingly, it has been found that centromeric repeats are transcribed by RNA polymerase II ( $\mathrm{Pol} \mathrm{II})$, even in the presence of repressive heterochromatin complexes (Cam et al. 2005; Djupedal et al. 2005; Kato et al. 2005; May et al. 2005). How Pol II transcribes repeat sequences within a highly condensed heterochromatin environment remains enigmatic. Recent studies have revealed that Epel facilitates transcription of heterochromatic repeats (Zofall and Grewal 2006). The HDAC Clr3 plays an opposing role in limiting Pol II accessibility, thereby promoting transcriptional silencing of heterochromatic domains (Yamada et al. 2005). Transcripts from the cenH repeat elements at the silent mat locus are not detectable in wild-type $S$. pombe strains, since they are processed into siRNAs. Loss of Clr3 results in increased Pol II occupancy at $c e n H$ and higher levels of $c e n H$ transcripts. Mutation of epe1 reduces Pol II and transcription at cenH in a clr3 background, suggesting a role for Epe1 in promoting Pol II accessibility and transcription at heterochromatic repeats. Given that Swi6 recruits Epe1 (Zofall and Grewal 2006; Isaac et al. 2007; Trewick et al. 2007), and that Swi6 and another HP1 protein, Chp2, recruit Clr3 (Sugiyama et al. 2007) to heterochromatin, a newly arising aspect of heterochromatin is that it recruits functionally antagonizing factors via Swi6 to tune up the balance between transcription and silencing of heterochromatic sequences, which is required for proper functioning of heterochromatin (Fig. 2; Zofall and Grewal 2006).

Epel appears to facilitate transcription of repeats in association with Swi6 in the context of a repressive chromatin environment (Zofall and Grewal 2006; Isaac et al. 2007). It remains to be established whether Epe1 directly recruits transcriptional machinery, which in turn destabilizes heterochromatin, or Epel first destabilizes heterochromatin components such as Swi6, thereby indirectly promoting Pol II transcription. More recent studies have revealed that $S$ phase of the cell cycle provides a short period of time during which heterochromatin becomes relatively accessible to Pol II for transcribing the underlying repeat sequences (Chen et al. 2008; Kloc et al. 2008). Taken together, the findings imply the existence of multiple mechanisms to transcribe heterochromatin. 


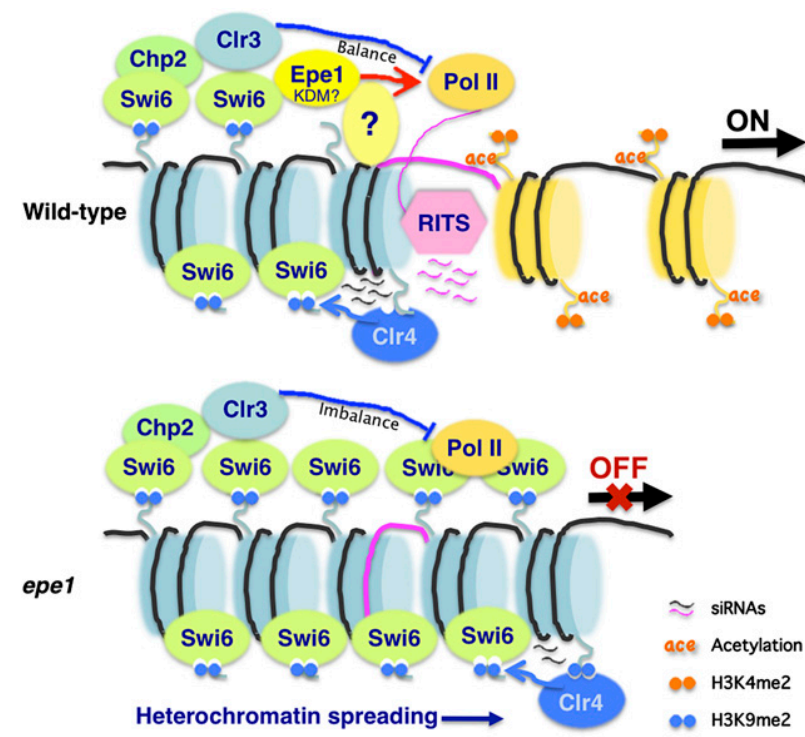

Figure 2. Model for the involvement of Epel in preventing spreading of heterochromatin into euchromatin. In S. pombe, the IRC elements (pink fiber) located at the boundaries of heterochromatin are transcribed by Pol II within the context of heterochromatin, are processed into siRNAs by the RITS complex, and serve as heterochromatin barrier elements. A DNA-binding factor or the RNAi pathway targets Clr4 HMT to heterochromatic regions (nucleosomes in blue) for $\mathrm{H} 3 \mathrm{~K} 9 \mathrm{me}$, which provides a binding site for the chromodomain of Swi6 (homolog of HP1). Swi6 recruits the JmjC domain protein Epe1. The histone deacetylase Clr3 is recruited by Swi6 and another chromodomain protein, Chp2. Clr3 limits Pol II accessibility to heterochromatic repeats and the IRC barrier elements, whereas Epe1 promotes its transcription. There is evidence for an unidentified protein (questionmark) that specifically targets Epe1 to heterochromatin/euchromatin boundaries. High concentrations of Epel and the resulting high levels of transcription at IRCs presumably provide an "open" chromatin environment that counteracts the repressive effects of heterochromatin. The balance between the opposing activities of Clr3 and Epel is critical for confining heterochromatin and its associated factors within a defined territory (Zofall and Grewal 2006). An epe 1 mutation leads predominantly to spreading of heterochromatin across euchromatic regions (nucleosomes in yellow) through self-reinforcing reactions between $\mathrm{H} 3 \mathrm{~K} 9 \mathrm{me}$ and Swi6. Binding of the Clr4 chromodomain to $\mathrm{H} 3 \mathrm{~K} 9 \mathrm{me}$ facilitates methylation of adjacent nucleosomes. Heterochromatin spreading can cause silencing of neighboring genes. It may be envisioned that, in a small population of cells, loss of Epe1 completely shuts off transcription of heterochromatic repeats and subsequent processing into siRNAs, which are essential for the stable maintenance of heterochromatin, thereby resulting in heterochromatin contraction. Histone lysine demethylase (KDM) activity has not been detected with Epel (Zofall and Grewal 2006).

\section{Epe1 promotes transcription of DNA barrier elements} and prevents spreading of heterochromatin across euchromatin

Supporting the previous cytological observation that Epe1 and Swi6 colocalize, ChIP-chip analyses of the distribution of Epe1 using antibodies against Epe1 and a microarray that covered the entire $S$. pombe genome re- vealed Epe1 at all the major heterochromatic loci, including centromeres, telomeres, the mat locus, and certain meiotic genes (Zofall and Grewal 2006). Epe1 association with heterochromatic loci depends on H3K9me and Swi6. Interestingly, close inspection of the enrichment of Epelat centromeric regions revealed prominent peaks at the inverted repeat $(I R C)$ elements located at boundaries of the heterochromatin domain. The Epe1 peaks coincide with a sharp decrease in heterochromatin marks such as H3K9me and Swi6. IRCs are transcribed by Pol II within the context of heterochromatin, correspond to hot spots of siRNA production (Cam et al. 2005), and have been shown to serve as heterochromatin barrier (or boundary) elements (Noma et al. 2006). Loss of Epe1, like deletion of IRCs, results in spreading of $\mathrm{H} 3 \mathrm{~K} 9 \mathrm{me}$ and Swi6 across centromeric sequences, indicating that Epel is required for barrier function of IRCs. An epe 1 mutation also leads to reduced Pol II occupancy at IRC1 and IRC3, and to reduced levels of their transcripts.

In view of these results, it seems likely that high concentrations of Epel and the resulting high levels of transcription at IRCs provide an "open" chromatin environment that counteracts the repressive effects of heterochromatin and prevent heterochromatin spreading across euchromatic sequences (Fig. 2; Grewal and Moazed 2003; Zofall and Grewal 2006). Remarkably, Epe1 localization within cen 1 and cen3 but not at IRC1 and IRC3 barrier elements fully depends on Swi6. Epe1 is still enriched at IRCs in the swi6 mutatnt (Zofall and Grewal 2006), raising the possibility of an unidentified factor that recruits Epe1 to IRCs, and suggesting a specific Swi6independent role for Epe1 at boundaries of heterochromatin. An intriguing possibility is that Epel interacts with proteins with similar function as DMM2 in $N$. crassa that recognize DNA barrier elements in S. pombe.

\section{The IBM1 JmjC domain protein in the flowering plant A. thaliana}

Three DNA methylation pathways cooperate to establish and maintain $5 \mathrm{mC}$

in the genome of $\mathrm{A}$. thaliana

Unlike in mammals, $5 \mathrm{mC}$ in the flowering plant $A$. thaliana is found in all sequence contexts: CG, CHG, and $\mathrm{CHH}$ (in which $\mathrm{H}$ is $\mathrm{A}, \mathrm{T}$, or C) (Chan et al. 2005). MET1, a homolog of the mammalian DNMT1, is responsible for the maintenance of CG methylation (Kankel et al. 2003). CMT3 is responsible for the majority of CHG and a small fraction of $\mathrm{CHH}$ methylation (Bartee et al. 2001; Lindroth et al. 2001). The KRYPTONITE (KYP) H3K9 HMT is required for cytosine methylation by CMT3 at CHG sites (Jackson et al. 2002; Malagnac et al. 2002). DOMAINS REARRANGED METHYLTRANSFERASE 2 (DRM2), which is homologous to the mammalian DNMT3, is required for RNA-directed DNA methylation $(\mathrm{RdDM})$ in all sequence contexts (Cao and Jacobsen 2002a,b). RdDM employs RNAi components-including RdRP (RDR2) (Xie et al. 2004), DICERLIKE3 (DCL3) (Xie et al. 2004; Daxinger et al. 2009), AGO4 (Zilberman et al. 
2003, 2004; Pontes et al. 2006), and plant-specific RNA polymerases Pol IV and Pol V (Herr et al. 2005; Kanno et al. 2005; Onodera et al. 2005) — to guide de novo methylation of DNA sequences homologous to 24-nucleotide (nt) siRNAs, and leads to transcriptional gene silencing (Matzke and Birchler 2005). Previous genome-wide mapping of DNA methylation in the Arabidopsis genome using methylated DNA immunoprecipitation (MeDIP) coupled with microarray analysis (Zhang et al. 2006; Zilberman et al. 2007), and, more recently, whole-genome shotgun sequencing of bisulphate-treated DNA /Cokus et al. 2008; Lister et al. 2008), revealed dense CG and non-CG methylation of repeated sequences and transposable elements (TEs) that are concentrated within pericentromeric heterochromatin domains. Unexpectedly, >30\% of expressed genes were also found methylated at relatively lower levels, exclusively in CG context in their coding, but not promoter, regions. The function of the gene body methylation is not yet known.

A ddm1-induced syndrome, bonsai (bns), caused by ectopic DNA methylation in A. thaliana

The SWI2/SNF2-like chromatin remodeling ATPase DECREASE IN DNA METHYLATION (DDM1) was originally identified through a genetic screen for mutants defective in DNA methylation in A. thaliana. DDM1 plays a vital role in controlling pericentromeric heterochromatin and TEs (Jeddeloh et al. 1999). DDM1 is involved in maintenance of both CG and non-CG methylation/Vongs et al. 1993; Jeddeloh et al. 1999). In $d d m 1$ plants, 180-bp centromeric (180CEN) repeats and most TEs lose DNA methylation, H3K9me2, and 24-nt siRNAs corresponding to TE sequences (Gendrel et al. 2002; Lippman et al. 2004). This results in transcriptional reactivation and transposition of TEs (Miura et al. 2001; Singer et al. 2001; Gendrel et al. 2002; Tsukahara et al. 2009). Repeated selfpollination of $d d m 1$ plants generates a variety of developmental abnormalities by inducing both genetic and epigenetic heritable alterations in loci other than DDM1 (Kakutani et al. 1996). Typically, phenotypes of $d d m 1$ induced epigenetic alleles (epi-alleles) are associated with loss of DNA methylation at normally methylated loci. For instance, $d d m 1$ induces a late-flowering phenotype through hypomethylation and ectopic expression of the imprinted homeobox gene FWA, which is normally silenced in embryonic plant tissues (Kakutani 1997; Soppe et al. 2000; Kinoshita et al. 2004).

Paradoxically, $d d m 1$ occasionally induces de novo DNA methylation and silencing of a normally unmethylated locus, SUPERMAN (SUP), resulting in morphological defects (Jacobsen et al. 2000). The bns phenotype, which is characterized by miniature plant morphologies with compact leaves and short shoots (Saze and Kakutani 2007), represents another example of a $d d m 1$-induced syndrome that is associated with ectopic de novo DNA methylation and transcriptional repression. The BNS locus encodes a homolog of a cell cycle regulator, Swm1/APC13 (Ufano et al. 1999; Yoon et al. 2002; Hall et al. 2003). The 3' downstream from $B N S$ is flanked by a truncated long interspersed nuclear element (LINE) retrotransposon in many Arabidopsis ecotypes. In wild-type plants, the LINE sequence is heavily methylated and transcriptionally silent, whereas BNS is free of cytosine methylation and is expressed. BNS transcripts extend into the LINE over its target site duplication (TSD) sequence. Strikingly, in bns lines, BNS was found heavily methylated in all sequence contexts, including $\mathrm{CHH}$ methylation, which is a characteristic of RdDM.

Consistent with the hypothesis that RdDM is responsible for the $d d m 1$-induced BNS methylation, 24-nt small RNAs corresponding to the methylated BNS coding region were detected in bns, but not wild-type, lines. Remarkably, the $d d m 1$ mutation did not induce the $B N S$ methylation in the Cvi ecotype background, which lacks the LINE flanking BNS (Saze and Kakutani 2007). The findings imply that transcriptional reactivation of the LINE flanking $B N S$ in the $d d m 1$ background results in the production of read-through $B N S$ antisense transcripts that form dsRNAs with $B N S$ mRNAs, which then trigger RdDM of $B N S$.

Identification of another mutation, ibm1, which induces BNS methylation

A genetic screen of a mutagenized plant population using methylation-sensitive restriction enzymes and PCRseeking novel mutations that, like $d d m 1$, induce de novo DNA methylation in the BNS sequence-led to the identification of IBM1 (Saze et al. 2008). The IBM1 gene turned out to encode a JmjC domain-containing protein that belongs to the JHDM2/KDM3 family conserved from plants to mammals. It is noteworthy that the BNS sequence was found methylated in the first generation in which ibm1 became homozygous. This contrasts the situation in the $d d m 1$ homozygous mutant in which several generations of self-pollination were required to detect $B N S$ methylation. Unlike the $d d m 1$ mutation, the ibm1 mutation did not cause DNA hypomethylation in heterochromatic sequences, including 180CEN repeats and $5 \mathrm{~S}$ ribosomal DNA. Moreover, whereas the $d d m 1$ mutation induced dense methylation at the BNS locus in all sequence contexts, the ibm1-induced de novo BNS methylation was found primarily at CHG sites, leaving $\mathrm{CHH}$ methylation negligible. These findings suggested that the mechanisms by which IBM1 and DDM1 limit DNA methylation in the BNS sequence are distinct, and that the primary targets for IBM1 are euchromatic sequences (Saze et al. 2008).

Taken together with the previous findings that KYP HMT controls CHG methylation by CMT3 DMT in $A$. thaliana, it was hypothesized that loss of IBM1 allows ectopic H3K9me by KYP at BNS, which subsequently directs CHG methylation by CMT3 (Saze et al. 2008). Supporting this proposal, ChIPs detected enrichment of H3K9me2 mark that colocalized with DNA methylation in the BNS sequence. Convincingly, the kyp and cmt3 mutations suppressed $B N S$ methylation in the $i b m 1$ background. Interestingly, the ibm 1 mutant showed more complex developmental defects than that caused 
by a loss-of-function allele of the BNS gene, and the kyp and cmt3 mutations rescued most, if not all, of the phenotypes, suggesting that the $i b m 1$ mutation induces ectopic de novo methylation of multiple genes, including $B N S$, thereby resulting in those abnormalities (Saze et al. 2008).

\section{IBM1 guards transcribed genes from CHG methylation}

Genome-wide analyses of the distribution of $5 \mathrm{mC}$ in wildtype and ibm 1 mutant lines revealed ectopic methylation in numerous genes, primarily at CHG sites (Miura et al. 2009). In contrast, the $i b m 1$ mutation did not increase DNA methylation of transposons, demonstrating that heterochromatic sequences are not the targets for IBM1. Importantly, unlike the $d d m 1$ mutation, the $i b m 1$ mutation induces genic methylation in the absence of adjacent transposons, and it typically causes heavier methylation at the central region of transcription units than that at the 5' - and 3'-terminal regions (Miura et al. 2009). The findings reinforce the notion that DDM1 and IBM1 use different mechanisms to control genic DNA methylation.

Interestingly, transcriptome analyses revealed that each region of increased DNA methylation coincides with a transcription unit, moderately transcribed genes and constitutively expressed genes are the most susceptible to the ibm1-induced CHG methylation, and long genes are susceptible to stronger methylation. This stronger methylation of longer genes resulting by mutation of $i b m 1$ was less evident in genes with low levels of expression, suggesting that the effect of the gene length also depends on transcription (Miura et al. 2009). It seems reasonable to speculate that the mechanism by which the $i b m 1$ mutation leads to genic CHG methylation is coupled with transcription, and that IBM1 functions to block KYP HMT or CMT3 DMT activity or remove inappropriately established $\mathrm{H} 3 \mathrm{~K} 9 \mathrm{me} 2$ by KYP during transcription (Fig. 3). It would be interesting to know whether KYP and/ or IBM1 interact with the transcription machinery. Consistent with the observation that the $i b m 1$ mutation does not cause lethality in Arabidopsis, preliminary results revealed that transcriptional repression is not always an outcome of the ibm1-induced global de novo CHG methylation of the gene body (Miura et al. 2009). Why the Arabidopsis genome does not employ mechanisms to keep the bodies of active genes completely free of CG methylation by MET1, as it does for CHG methylation by CMT3, remains a mystery.

\section{Possible functional interaction between IBM1 and DDM1}

Curiously, methylation at the BNS locus was found enriched in the $3^{\prime}$ region of transcribed sequence near the flanking LINE in the ibm1 mutant (Saze et al. 2008). One could imagine that IBM1 and DDM1 might cooperate to prevent the spreading of methylation over genic regions in rare cases where genes are flanked by transposons. It would be interesting to know whether the pattern of BNS methylation induced by the ibm1 mutation changes in the absence of the neighboring LINE in
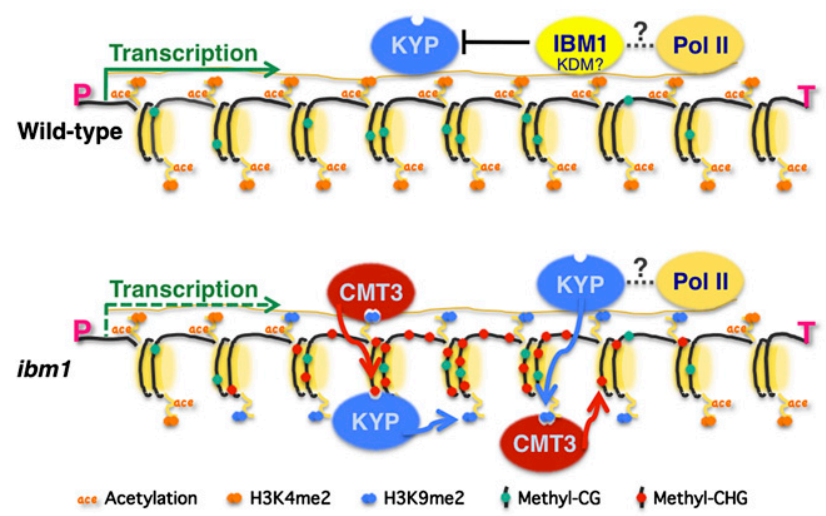

Figure 3. Model for the involvement of IBM1 in protecting transcribed genes from CHG methylation. In A. thaliana, DNA $5 \mathrm{mC}$ of genes is limited to CG sites. IBM1 prevents KYP HMT from inappropriate deposition of $\mathrm{H} 3 \mathrm{~K} 9 \mathrm{me}$ on the bodies of active genes by either suppressing KYP activity or demethylating $\mathrm{H} 3 \mathrm{~K} 9 \mathrm{me}$ in a transcription-coupled manner. It is not known whether IBM and KYP interact with Pol II. An ibm1 mutation allows KYP to methylate $\mathrm{H} 3 \mathrm{~K} 9$ within transcribed regions. The chromodomain of the DMT CMT3 recognizes dual methylation marks at $\mathrm{H} 3 \mathrm{~K} 9$ and $\mathrm{H} 3 \mathrm{~K} 27$, and methylates DNA preferentially in the CHG context. The SRA domain of KYP binds to $5 \mathrm{mC}$ to facilitate methylation of adjacent nucleosomes. The ectopic CHG methylation of the gene body is not invariably associated with transcriptional repression. The central portions of long transcribed genes are most frequently subjected to ibm1-induced de novo methylation by unknown mechanisms. RdDM components do not seem to be involved in the process. The JmjC domain of IBM1 has all of the key amino acid residues critical for lysine demethylase (KDM) activity, but the activity has not been detected with IBM1 (Saze et al. 2008; Miura et al. 2009). (P) Promoter; (T) terminator.

the Cvi ecotype background. Remarkably, ddm1 ibm1 double mutants exhibit dramatically enhanced developmental defects, involving smaller leaves, slower growth, and complete sterility, compared with $d d m 1$ or $i b m 1$ single mutants (Saze et al. 2008). Similar genome-wide mapping of $5 \mathrm{mC}$ and transcription profiling in the $d d \mathrm{~m} 1$ ibm1 double mutant in comparison with the ibm1 or $d d m 1$ single mutant may provide insights into functional interactions between DDM1and IBM1.

\section{Viewpoint}

\section{Are Epe1, IBM1, and DMM-1 histone demethylases?}

The JmjC domain has been implicated in active removal of methyl groups from histones (Klose et al. 2006a,b; Tsukada et al. 2006). JmjC histone demethylases can demethylate mono-, di-, and trimethylated lysine by an oxidative mechanism that requires $\mathrm{Fe}(\mathrm{II})$ and $\alpha$-ketoglutarate $(\alpha \mathrm{KG})$ as cofactors. Demethylation is thought to occur by direct hydroxylation of the methyl group, resulting in an unstable hydroxymethyl product that is released spontaneously as formaldehyde (Trewick et al. 2005; Klose et al. 2006a). Three amino acid residues within the JmjC domain bind to the $\mathrm{Fe}(\mathrm{II})$ cofactor, and two additional residues bind 
to $\alpha \mathrm{KG}$. The JmjC domain of the Neurospora DMM-1 and the Arabidopsis IBM1 have the highly conserved residues within the predicted cofactor-binding sites known to be required for demethylase activity, whereas that of the $S$. pombe Epel lacks a conserved residue within the Fe(II)-binding site (Ayoub et al. 2003; Zofall and Grewal 2006; Trewick et al. 2007). Histone demethylase activity has not been detected for either of the proteins. Nonetheless, conserved residues in the JmjC domain of Epe1 and DMM-1 have been shown to be essential for their in vivo functions (Zofall and Grewal 2006; Trewick et al. 2007; Honda et al. 2010).

Based on structural homology between Epel and another JmjC domain protein, $\mathrm{FIH}$, which hydroxylates itself at Asn803 to repress its binding to the histone acetylase p300 (Schofield and Ratcliffe 2005), it has been proposed that Epe1 may also hydroxylate itself or another heterochromatin protein, such as Swi6, to modulate the stability of heterochromatin (Trewick et al. 2005, 2007). Moreover, the lysine demethylase LSD1, which was originally identified as a histone $\mathrm{H} 3 \mathrm{~K} 9 \mathrm{me} 1 / 2$ demethylase in human cells, has been found to demethylate K370me1/2 of the p53 tumor suppressor in vitro (J Huang et al. 2007). The question of whether $\mathrm{JmjC}$ domain proteins are able to demethylate nonhistone proteins is still open. Interestingly, a $d m m-1$ substitution mutation (H216A) in a conserved residue within the Fe(II)-binding site of the JmjC domain, which presumably abolishes the catalytic activity of DMM-1, results in the spreading of DMM-1 from RIP'd regions to adjacent sequences, phenocopying the effect of the $d m m-2$ mutation. This raises the possibility that DMM-1 hydroxylates/demethylates itself or DMM-2 to promote its interaction with DMM-2.

\section{Concluding remarks}

The first JmjC domain protein was identified in a gene trap screen for factors involved in neural tube formation (Takeuchi et al. 1995). The homozygous mutant mice showed abnormal groove formation on the neural plate and a defect in neural tube closure. Takeuchi et al. (1995) called this mutation jumonji ( $j m j)$, since homozygous mutant mice usually form an additional groove at the future midbrain-hindbrain boundary that intersects the normal neural groove, resulting in a "cross" -shaped cut on the neural plate (jumonji is Japanese for cruciform) (Fig. 4). Recent studies suggest that the $j m j$ phenotype on the neural plate results from an enhanced proliferation of abnormal layers of the neural epithelial cells at the midbrain-hindbrain boundary, which is caused by an increased expression of cyclin D1 (Takeuchi et al. 2006). The molecular details of how the Jmj protein downregulates cyclin D1 expression at the boundary are not known. LSD1, which is evolutionarily conserved from $S$. pombe to human, represents the second class of protein associated with histone demethylase activity, and has been implicated in the propagation of euchromatin and heterochromatin by demethylating histone $\mathrm{H} 3 \mathrm{~K} 9 \mathrm{me}$ and H3K4me, respectively (Metzger et al. 2005; Lan et al. 2007; Rudolph et al. 2007). Whether LSD1 and JmjC domain
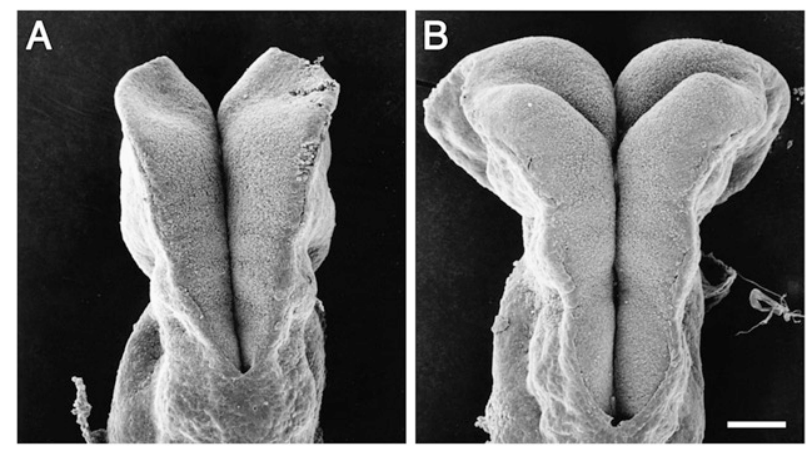

Figure 4. Abnormal groove formation on the neural plate of jumonji homozygous mutant mouse embryos. Scanning electron micrographs of dorsal views of wild-type $(A)$ and jumonji mutant $(B)$ mouse embryos at embryonic day 8.5 (nine-somite stage). Bar, $100 \mu \mathrm{m}$. Photographs courtesy of Takashi Takeuchi.

proteins cooperate to control euchromatin/heterochromatin territories remains to be explored. In view of the roles for Epe1, IBM1, and DMM-1 in protecting euchromatin from heterochromatic marks, it will be interesting to learn if mammals use similar mechanisms.

\section{Acknowledgments}

I am grateful to Eric Selker, Shiv Grewal, Tetsuji Kakutani, and Marjori Matzke for reviewing the paper; Maria Siomos for editing the manuscript; and Takashi Takeuchi for unpublished images of the jumonji phenotype. I thank Jill Andersen for encouragement. My research is supported by the Austrian FWF Stand Alone grant P21389-B03.

\section{References}

Aagaard L, Laible G, Selenko P, Schmid M, Dorn R, Schotta G, Kuhfittig S, Wolf A, Lebersorger A, Singh PB, et al. 1999. Functional mammalian homologues of the Drosophila PEVmodifier Sulvar)3-9 encode centromere-associated proteins which complex with the heterochromatin component M31. EMBO I 18: 1923-1938.

Ayoub N, Noma K, Isaac S, Kahan T, Grewal SIS, Cohen A. 2003. A novel jmjC domain protein modulates heterochromatization in fission yeast. Mol Cell Biol 23: 4356-4370.

Baker WK. 1968. Position-effect variegation. Adv Genet 14: 133169.

Bannister AJ, Zegerman P, Partridge JF, Miska EA, Thomas JO, Allshire RC, Kouzarides T. 2001. Selective recognition of methylated lysine 9 on histone H3 by the HP1 chromo domain. Nature 410: 120-124.

Bartee L, Malagnac F, Bender J. 2001. Arabidopsis cmt3 chromomethylase mutations block non-CG methylation and silencing of an endogenous gene. Genes Dev 15: 1753-1758.

Bayne EH, Allshire RC. 2005. RNA-directed transcriptional gene silencing in mammals. Trends Genet 21: 370-373.

Blasco MA. 2007. The epigenetic regulation of mammalian telomeres. Nat Rev Genet 8: 299-309.

Buschhausen G, Wittig B, Graessmann M, Graessmann A. 1987. Chromatin structure is required to block transcription of the methylated herpes-simplex virus thymidine kinase gene. Proc Natl Acad Sci 84: 1177-1181.

Cam HP, Sugiyama T, Chen ES, Chen X, FitzGerald PC, Grewal SIS. 2005. Comprehensive analysis of heterochromatin- and 
RNAi-mediated epigenetic control of the fission yeast genome. Nat Genet 37: 809-819.

Cambareri EB, Jensen BC, Schabtach E, Selker EU. 1989. Repeatinduced G-C TO A-T mutations in Neurospora. Science 244: 1571-1575.

Cambareri EB, Foss HM, Rountree MR, Selker EU, Kinsey JA. 1996. Epigenetic control of a transposon-inactivated gene in Neurospora is dependent on DNA methylation. Genetics 143: $137-146$.

Cao XF, Jacobsen SE. 2002a. Locus-specific control of asymmetric and CpNpG methylation by the DRM and CMT3 methyltransferase genes. Proc Natl Acad Sci 99: 16491-16498.

Cao XF, Jacobsen SE. 2002b. Role of the Arabidopsis DRM methyltransferases in de novo DNA methylation and gene silencing. Curr Biol 12: 1138-1144.

Chan SWL, Henderson IR, Jacobsen SE. 2005. Gardening the genome: DNA methylation in Arabidopsis thaliana. Nat Rev Genet 6: 351-360.

Chen ES, Zhang K, Nicolas E, Cam HP, Zofall M, Grewal SI. 2008. Cell cycle control of centromeric repeat transcription and heterochromatin assembly. Nature 451: 734-737.

Chicas A, Cogoni C, Macino G. 2004. RNAi-dependent and RNAi-independent mechanisms contribute to the silencing of RIPed sequences in Neurospora crassa. Nucleic Acids Res 32: 4237-4243.

Chicas A, Forrest EC, Sepich S, Cogoni C, Macino G. 2005. Small interfering RNAs that trigger posttranscriptional gene silencing are not required for the histone H3 Lys9 methylation necessary for transgenic tandem repeat stabilization in Neurospora crassa. Mol Cell Biol 25: 3793-3801.

Cogoni C. 2001. Homology-dependent gene silencing mechanisms in fungi. Annu Rev Microbiol 55: 381-406.

Cogoni C, Macino G. 1999a. Gene silencing in Neurospora crassa requires a protein homologous to RNA-dependent RNA polymerase. Nature 399: 166-169.

Cogoni C, Macino G. 1999b. Posttranscriptional gene silencing in Neurospora by a RecQ DNA helicase. Science 286: 23422344.

Cogoni C, Irelan JT, Schumacher M, Schmidhauser TJ, Selker EU, Macino G. 1996. Transgene silencing of the al-1 gene in vegetative cells of Neurospora is mediated by a cytoplasmic effector and does not depend on DNA-DNA interactions or DNA methylation. EMBO I 15: 3153-3163.

Cokus SJ, Feng SH, Zhang XY, Chen ZG, Merriman B, Haudenschild CD, Pradhan S, Nelson SF, Pellegrini M, Jacobsen SE. 2008. Shotgun bisulphite sequencing of the Arabidopsis genome reveals DNA methylation patterning. Nature 452: 215-219.

Daxinger L, Kanno T, Bucher E, van der Winden J, Naumann U, Matzke AJM, Matzke M. 2009. A stepwise pathway for biogenesis of 24-nt secondary siRNAs and spreading of DNA methylation. EMBO $J$ 28: 48-57.

Djupedal I, Portoso M, Spahr H, Bonilla C, Gustafsson CM, Allshire RC, Ekwall K. 2005. RNA Pol II subunit Rpb7 promotes centromeric transcription and RNAi-directed chromatin silencing. Genes Dev 19: 2301-2306.

Eissenberg JC. 1989. Position effect variegation in Drosophila: Towards a genetics of chromatin assembly. Bioessays 11: 14-17.

Eissenberg JC, Reuter G. 2009. Cellular mechanism for targeting heterochromatin formation in Drosophila. Int Rev Cell Mol Biol 273: 1-47.

Eissenberg JC, James TC, Fosterhartnett DM, Hartnett T, Ngan V, Elgin SCR. 1990. Mutation in a heterochromatin-specific chromosomal protein is associated with suppression of position-effect variegation in Drosophila melanogaster. Proc Natl Acad Sci 87: 9923-9927.
Folco HD, Pidoux AL, Urano T, Allshire RC. 2008. Heterochromatin and RNAi are required to establish CENP-A chromatin at centromeres. Science 319: 94-97.

Foss HM, Roberts CJ, Claeys KM, Selker EU. 1993. Abnormal chromosome behavior in Neurospora mutants defective in DNA methylation. Science 262: 1737-1741.

Freitag M, Hickey PC, Khlafallah TK, Read ND, Selker EU. 2004a. HP1 is essential for DNA methylation in Neurospora. Mol Cell 13: 427-434.

Freitag M, Lee DW, Kothe GO, Pratt RJ, Aramayo R, Selker EU. 2004b. DNA methylation is independent of RNA interference in Neurospora. Science 304: 1939.

Fujita N, Watanabe S, Ichimura T, Tsuruzoe S, Shinkai Y, Tachibana M, Chiba T, Nakao M. 2003. Methyl-CpG binding domain 1 (MBD1) interacts with the Suv39h1-HP1 heterochromatic complex for DNA methylation-based transcriptional repression. J Biol Chem 278: 24132-24138.

Galagan JE, Selker EU. 2004. RIP: The evolutionary cost of genome defense. Trends Genet 20: 417-423.

Galagan JE, Calvo SE, Borkovich KA, Selker EU, Read ND, Jaffe D, FitzHugh W, Ma LJ, Smirnov S, Purcell S, et al. 2003. The genome sequence of the filamentous fungus Neurospora crassa. Nature 422: 859-868.

Gaszner M, Felsenfeld G. 2006. Insulators: Exploiting transcriptional and epigenetic mechanisms. Nat Rev Genet 7: 703713.

Gendrel AV, Lippman Z, Yordan C, Colot V, Martienssen RA. 2002. Dependence of heterochromatic histone H3 methylation patterns on the Arabidopsis gene DDM1. Science 297: 1871-1873.

Grewal SI, Elgin SC. 2007. Transcription and RNA interference in the formation of heterochromatin. Nature 447: 399-406.

Grewal SIS, Jia ST. 2007. Heterochromatin revisited. Nat Rev Genet 8: 35-46.

Grewal SIS, Moazed D. 2003. Heterochromatin and epigenetic control of gene expression. Science 301: 798-802.

Grunstein M. 1998. Yeast heterochromatin: Regulation of its assembly and inheritance by histones. Cell 93: 325-328.

Hall IM, Shankaranarayana GD, Noma KI, Ayoub N, Cohen A, Grewal SIS. 2002. Establishment and maintenance of a heterochromatin domain. Science 297: 2232-2237.

Hall MC, Torres MP, Schroeder GK, Borchers CH. 2003. Mnd2 and Swm1 are core subunits of the Saccharomyces cerevisiae anaphase-promoting complex. J Biol Chem 278: 16698-16705.

Henikoff S. 1990. Position-effect variegation after 60 years. Trends Genet 6: 422-426.

Hennig W. 1999. Heterochromatin. Chromosoma 108: 1-9.

Herr AJ, Jensen MB, Dalmay T, Baulcombe DC. 2005. RNA polymerase IV directs silencing of endogenous DNA. Science 308: $118-120$.

Honda S, Selker EU. 2008. Direct interaction between DNA methyltransferase DIM-2 and HP1 is required for DNA methylation in Neurospora crassa. Mol Cell Biol 28: 60446055.

Honda S, Lewis ZA, Huarte M, Cho LY, David LL, Shi Y, Selker EU. 2010. The DMM complex prevents spreading of DNA methylation from transposons to nearby genes in Neurospora crassa. Genes Dev 24: 443-454.

Huang J, Sengupta R, Espejo AB, Lee MG, Dorsey JA, Richter M, Opravil S, Shiekhattar R, Bedford MT, Jenuwein T, et al. 2007. p53 is regulated by the lysine demethylase LSD1. Nature 449: 105-108.

Huang S, Li X, Yusufzai TM, Qiu Y, Felsenfeld G. 2007. USF1 recruits histone modification complexes and is critical for maintenance of a chromatin barrier. Mol Cell Biol 27: 79918002 . 
Huisinga KL, Brower-Toland B, Elgin SCR. 2006. The contradictory definitions of heterochromatin: Transcription and silencing. Chromosoma 115: 110-122.

Irelan JT, Selker EU. 1997. Cytosine methylation associated with repeat-induced point mutation causes epigenetic gene silencing in Neurospora crassa. Genetics 146: 509-523.

Isaac S, Walfridsson J, Zohar T, Lazar D, Kahan T, Ekwall K, Cohen A. 2007. Interaction of Epel with the heterochromatin assembly pathway in Schizosaccharomyces pombe. Genetics 175: 1549-1560.

Jackson JP, Lindroth AM, Cao XF, Jacobsen SE. 2002. Control of CpNpG DNA methylation by the KRYPTONITE histone H3 methyltransferase. Nature 416: 556-560.

Jacobsen SE, Sakai H, Finnegan EJ, Cao XF, Meyerowitz EM. 2000. Ectopic hypermethylation of flower-specific genes in Arabidopsis. Curr Biol 10: 179-186.

Jeddeloh JA, Stokes TL, Richards EJ. 1999. Maintenance of genomic methylation requires a SW12/SNF2-like protein. Nat Genet 22: 94-97.

Jenuwein T, Allis CD. 2001. Translating the histone code. Science 293: 1074-1080.

Jia ST, Noma K, Grewal SIS. 2004a. RNAi-independent heterochromatin nucleation by the stress-activated ATF/CREB family proteins. Science 304: 1971-1976.

Jia ST, Yamada T, Grewal SIS. 2004b. Heterochromatin regulates cell type-specific long-range chromatin interactions essential for directed recombination. Cell 119: 469-480.

Johnson LM, Bostick M, Zhang XY, Kraft E, Henderson I, Callis J, Jacobsen SE. 2007. The SRA methyl-cytosine-binding domain links DNA and histone methylation. Curr Biol 17: 379-384.

Kakutani T. 1997. Genetic characterization of late-flowering traits induced by DNA hypomethylation mutation in Arabidopsis thaliana. Plant J 12: 1447-1451.

Kakutani T, Jeddeloh JA, Flowers SK, Munakata K, Richards EJ. 1996. Developmental abnormalities and epimutations associated with DNA hypomethylation mutations. Proc Natl Acad Sci 93: 12406-12411.

Kanellopoulou C, Muljo SA, Kung AL, Ganesan S, Drapkin R, Jenuwein $T$, Livingston DM, Rajewsky K. 2005. Dicerdeficient mouse embryonic stem cells are defective in differentiation and centromeric silencing. Genes Dev 19: 489-501.

Kankel MW, Ramsey DE, Stokes TL, Flowers SK, Haag JR, Jeddeloh JA, Riddle NC, Verbsky ML, Richards EJ. 2003. Arabidopsis MET1 cytosine methyltransferase mutants. Genetics 163: 1109-1122.

Kanno T, Huettel B, Mette MF, Aufsatz W, Jaligot E, Daxinger L, Kreil DP, Matzke M, Matzke AJM. 2005. Atypical RNA polymerase subunits required for RNA-directed DNA methylation. Nat Genet 37: 761-765.

Kato $\mathrm{H}$, Goto DB, Martienssen RA, Urano T, Furukawa $\mathrm{K}$, Murakami Y. 2005. RNA polymerase II is required for RNAi-dependent heterochromatin assembly. Science 309: 467-469.

Keshet I, Liemanhurwitz J, Cedar H. 1986. DNA methylation affects the formation of active chromatin. Cell 44: 535543.

Kinoshita T, Miura A, Choi YH, Kinoshita Y, Cao XF, Jacobsen SE, Fischer RL, Kakutani T. 2004. One-way control of FWA imprinting in Arabidopsis endosperm by DNA methylation. Science 303: 521-523.

Kloc A, Martienssen R. 2008. RNAi, heterochromatin and the cell cycle. Trends Genet 24: 511-517.

Kloc A, Zaratiegui M, Nora E, Martienssen R. 2008. RNA interference guides histone modification during the $S$ phase of chromosomal replication. Curr Biol 18: 490-495.
Klose RJ, Kallin EM, Zhang Y. 2006a. JmjC-domain-containing proteins and histone demethylation. Nat Rev Genet 7: 715727.

Klose RJ, Yamane K, Bae YJ, Zhang DZ, Erdjument-Bromage H, Tempst P, Wong JM, Zhang Y. 2006b. The transcriptional repressor JHDM3A demethylates trimethyl histone H3 lysine 9 and lysine 36. Nature 442: 312-316.

Kouzminova E, Selker EU. 2001. dim-2 encodes a DNA methyltransferase responsible for all known cytosine methylation in Neurospora. EMBO J 20: 4309-4323.

Lachner M, Jenuwein T. 2002. The many faces of histone lysine methylation. Curr Opin Cell Biol 14: 286-298.

Lachner M, O'Carroll N, Rea S, Mechtler K, Jenuwein T. 2001. Methylation of histone $\mathrm{H} 3$ lysine 9 creates a binding site for HP1 proteins. Nature 410: 116-120.

Lan F, Zaratiegui M, Villén J, Vaughn MW, Verdel A, Huarte M, Shi Y, Gygi SP, Moazed D, Martienssen RA, et al. 2007. S. pombe LSD1 homologs regulate heterochromatin propagation and euchromatic gene transcription. Mol Cell 26: 89-101.

Law JA, Jacobsen SE. 2010. Establishing, maintaining and modifying DNA methylation patterns in plants and animals. Nat Rev Genet 11: 204-220.

Lehnertz B, Ueda Y, Derijck A, Braunschweig U, Perez-Burgos L, Kubicek S, Chen TP, Li E, Jenuwein T, Peters A. 2003. Suv39h-mediated histone H3 lysine 9 methylation directs DNA methylation to major satellite repeats at pericentric heterochromatin. Curr Biol 13: 1192-1200.

Lewis ZA, Honda S, Khlafallah TK, Jeffress JK, Freitag M, Mohn F, Schubeler D, Selker EU. 2009. Relics of repeat-induced point mutation direct heterochromatin formation in Neurospora crassa. Genome Res 19: 427-437.

Lindroth AM, Cao XF, Jackson JP, Zilberman D, McCallum CM, Henikoff S, Jacobsen SE. 2001. Requirement of CHROMOMETHYLASE3 for maintenance of CpXpG methylation. Science 292: 2077-2080.

Lindroth AM, Shultis D, Jasencakova Z, Fuchs J, Johnson L, Schubert D, Patnaik D, Pradhan S, Goodrich J, Schubert I, et al. 2004. Dual histone H3 methylation marks at lysines 9 and 27 required for interaction with CHROMOMETHYLASE3. EMBO I 23: 4146-4155.

Lippman Z, Martienssen R. 2004. The role of RNA interference in heterochromatic silencing. Nature 431: 364-370.

Lippman Z, Gendrel AV, Black M, Vaughn MW, Dedhia N, McCombie WR, Lavine K, Mittal V, May B, Kasschau KD, et al. 2004. Role of transposable elements in heterochromatin and epigenetic control. Nature 430: 471-476.

Lister R, O'Malley RC, Tonti-Filippini J, Gregory BD, Berry CC, Millar AH, Ecker JR. 2008. Highly integrated single-base resolution maps of the epigenome in Arabidopsis. Cell 133: 523-536.

Litt MD, Simpson M, Gaszner M, Allis CD, Felsenfeld G. 2001. Correlation between histone lysine methylation and developmental changes at the chicken $\beta$-globin locus. Science 293: 2453-2455.

Luger K, Mader AW, Richmond RK, Sargent DF, Richmond TJ. 1997. Crystal structure of the nucleosome core particle at 2.8 angstrom resolution. Nature 389: 251-260.

MacPherson S, Larochelle M, Turcotte B. 2006. A fungal family of transcriptional regulators: The zinc cluster proteins. Microbiol Mol Biol Rev 70: 583-604.

Malagnac F, Bartee L, Bender J. 2002. An Arabidopsis SET domain protein required for maintenance but not establishment of DNA methylation. EMBO J 21: 6842-6852.

Margolin BS, Garrett-Engele PW, Stevens JN, Fritz DY, GarrettEngele C, Metzenberg RL, Selker EU. 1998. A methylated Neurospora 5S rRNA pseudogene contains a transposable 
element inactivated by repeat-induced point mutation. Genetics 149: 1787-1797.

Martens JHA, O'Sullivan RJ, Braunschweig U, Opravil S, Radolf M, Steinlein P, Jenuwein T. 2005. The profile of repeatassociated histone lysine methylation states in the mouse epigenome. EMBO J 24: 800-812.

Martienssen RA. 2003. Maintenance of heterochromatin by RNA interference of tandem repeats. Nat Genet 35: 213214.

Matzke MA, Birchler JA. 2005. RNAi-mediated pathways in the nucleus. Nat Rev Genet 6: 24-35.

May BP, Lippman ZB, Fang YD, Spector DL, Martienssen RA. 2005. Differential regulation of strand-specific transcripts from Arabidopsis centromeric satellite repeats. PLoS Genet 1: 705-714.

Metzger E, Wissmann M, Yin N, Müller JM, Schneider R, Peters AH, Günther T, Buettner R, Schüle R. 2005. LSD1 demethylates repressive histone marks to promote androgenreceptor-dependent transcription. Nature 437: 436-439.

Miao VPW, Freitag M, Selker EU. 2000. Short TpA-rich segments of the zeta-eta region induce DNA methylation in Neurospora crassa. J Mol Biol 300: 249-273.

Miura A, Yonebayashi S, Watanabe K, Toyama T, Shimada H, Kakutani T. 2001. Mobilization of transposons by a mutation abolishing full DNA methylation in Arabidopsis. Nature 411: 212-214.

Miura A, Nakamura M, Inagaki S, Kobayashi A, Saze H, Kakutani T. 2009. An Arabidopsis jmjC domain protein protects transcribed genes from DNA methylation at CHG sites. EMBO J 28: 1078-1086.

Morris KV, Chan SWL, Jacobsen SE, Looney DJ. 2004. Small interfering RNA-induced transcriptional gene silencing in human cells. Science 305: 1289-1292.

Motamedi MR, Verdel A, Colmenares SU, Gerber SA, Gygi SP, Moazed D. 2004. Two RNAi complexes, RITS and RDRC, physically interact and localize to noncoding centromeric RNAs. Cell 119: 789-802.

Nakayam J, Rice JC, Strahl BD, Allis CD, Grewal SIS. 2001. Role of histone $\mathrm{H} 3$ lysine 9 methylation in epigenetic control of heterochromatin assembly. Science 292: 110-113.

Noma K, Allis CD, Grewal SIS. 2001. Transitions in distinct histone $\mathrm{H} 3$ methylation patterns at the heterochromatin domain boundaries. Science 293: 1150-1155.

Noma K, Sugiyama T, Cam H, Verdel A, Zofall M, Jia ST, Moazed D, Grewal SIS. 2004. RITS acts in cis to promote RNA interference-mediated transcriptional and post-transcriptional silencing. Nat Genet 36: 1174-1180.

Noma KI, Cam HP, Maraia RJ, Grewal SIS. 2006. A role for TFIIIC transcription factor complex in genome organization. Cell 125: 859-872.

Onodera Y, Haag JR, Ream T, Nunes PC, Pontes O, Pikaard CS. 2005. Plant nuclear RNA polymerase IV mediates siRNA and DNA methylation-dependent heterochromatin formation. Cell 120: 613-622.

Ooi SKT, Qiu C, Bernstein E, Li KQ, Jia D, Yang Z, ErdjumentBromage H, Tempst P, Lin SP, Allis CD, et al. 2007. DNMT3L connects unmethylated lysine 4 of histone H3 to de novo methylation of DNA. Nature 448: 714-717.

Peters A, O'Carroll D, Scherthan H, Mechtler K, Sauer S, Schofer C, Weipoltshammer K, Pagani M, Lachner M, Kohlmaier A, et al. 2001. Loss of the Suv39h histone methyltransferases impairs mammalian heterochromatin and genome stability. Cell 107: 323-337.

Pidoux AL, Allshire RC. 2005. The role of heterochromatin in centromere function. PhilosTrans R Soc B Biol Sci 360: 569579 .
Pontes O, Li CF, Nunes PC, Haag J, Ream T, Vitins A, Jacobsen SE, Pikaard CS. 2006. The Arabidopsis chromatin-modifying nuclear siRNA pathway involves a nucleolar RNA processing center. Cell 126: 79-92.

Rea S, Eisenhaber F, O'Carroll N, Strahl BD, Sun ZW, Schmid M, Opravil S, Mechtler K, Ponting CP, Allis CD, et al. 2000. Regulation of chromatin structure by site-specific histone H3 methyltransferases. Nature 406: 593-599.

Reeves R. 2001. Molecular biology of HMGA proteins: Hubs of nuclear function. Gene 277: 63-81.

Richards EJ, Elgin SC. 2002. Epigenetic codes for heterochromatin formation and silencing: Rounding up the usual suspects. Cell 108: 489-500.

Rountree MR, Selker EU. 1997. DNA methylation inhibits elongation but not initiation of transcription in Neurospora crassa. Genes Dev 11: 2383-2395.

Rudolph T, Yonezawa M, Lein S, Heidrich K, Kubicek S, Schäfer C, Phalke S, Walther M, Schmidt A, Jenuwein T, et al. 2007. Heterochromatin formation in Drosophila is initiated through active removal of H3K4 methylation by the LSD1 homolog SU(VAR)3-3. Mol Cell 26: 103-115.

Sarraf SA, Stancheva I. 2004. Methyl-CpG binding protein MBD1 couples histone $\mathrm{H} 3$ methylation at lysine 9 by SETDB1 to DNA replication and chromatin assembly. Mol Cell 15: 595-605.

Saze H, Kakutani T. 2007. Heritable epigenetic mutation of a transposon-flanked Arabidopsis gene due to lack of the chromatin-remodeling factor DDM1. EMBO / 26: 3641-3652.

Saze H, Shiraishi A, Miura A, Kakutani T. 2008. Control of genic DNA methylation by a jmjC domain-containing protein in Arabidopsis thaliana. Science 319: 462-465.

Schoeftner S, Blasco MA. 2009. A 'higher order' of telomere regulation: Telomere heterochromatin and telomeric RNAs. EMBO I 28: 2323-2336.

Schofield CJ, Ratcliffe PJ. 2005. Signalling hypoxia by HIF hydroxylases. Biochem Biophys Res Commun 338: 617-626.

Schotta G, Ebert A, Krauss V, Fischer A, Hoffmann J, Rea S, Jenuwein T, Dorn R, Reuter G. 2002. Central role of Drosophila SU(VAR)3-9 in histone H3-K9 methylation and heterochromatic gene silencing. EMBO I 21: 1121-1131.

Schotta G, Ebert A, Dorn R, Reuter G. 2003. Position-effect variegation and the genetic dissection of chromatin regulation in Drosophila. Semin Cell Dev Biol 14: 67-75.

Schueler MG, Sullivan BA. 2006. Structural and functional dynamics of human centromeric chromatin. Annu Rev Genomics Hum Genet 7: 301-313.

Selker EU. 1990. Premeiotic instability of repeated sequences in Neurospora-crassa. Annu Rev Genet 24: 579-613.

Selker EU. 2004. Genome defense and DNA methylation in Neurospora. Cold Spring Harb Symp Quant Biol 69: 119-124.

Selker EU, Fritz DY, Singer MJ. 1993. dense nonsymmetrical DNA methylation resulting from repeat-induced point mutation in Neurospora. Science 262: 1724-1728.

Selker EU, Freitag M, Kothe GO, Margolin BS, Rountree MR, Allis CD, Tamaru H. 2002. Induction and maintenance of nonsymmetrical DNA methylation in Neurospora. Proc Natl Acad Sci 99: 16485-16490.

Selker EU, Tountas NA, Cross SH, Margolin BS, Murphy JG, Bird AP, Freitag M. 2003. The methylated component of the Neurospora crassa genome. Nature 422: 893-897.

Singer MJ, Marcotte BA, Selker EU. 1995. DNA methylation associated with repeat-induced point mutation in Neurospora-crassa. Mol Cell Biol 15: 5586-5597.

Singer T, Yordan C, Martienssen RA. 2001. Robertson's Mutator transposons in A-thaliana are regulated by the chromatinremodeling gene Decrease in DNA Methylation (DDM1). Genes Dev 15: 591-602. 
Slotkin RK, Martienssen R. 2007. Transposable elements and the epigenetic regulation of the genome. Nat Rev Genet 8: $272-285$.

Soppe WIJ, Jacobsen SE, Alonso-Blanco C, Jackson JP, Kakutani T, Koornneef M, Peeters AJM. 2000. The late flowering phenotype of fwa mutants is caused by gain-of-function epigenetic alleles of a homeodomain gene. Mol Cell 6: 791802.

Sugiyama T, Cam H, Verdel A, Moazed D, Grewal SIS. 2005. RNA-dependent RNA polymerase is an essential component of a self-enforcing loop coupling heterochromatin assembly to siRNA production. Proc Natl Acad Sci 102: 152-157.

Sugiyama T, Cam HP, Sugiyama R, Noma K, Zofall M, Kobayashi R, Grewal SIS. 2007. SHREC, an effector complex for heterochromatic transcriptional silencing. Cell 128: 491-504.

Sun FL, Haynes K, Simpson CL, Lee SD, Collins L, Wuller J, Eissenberg JC, Elgin SCR. 2004. Cis-acting determinants of heterochromatin formation on Drosophila melanogaster chromosome four. Mol Cell Biol 24: 8210-8220.

Suzuki MM, Bird A. 2008. DNA methylation landscapes: Provocative insights from epigenomics. Nat Rev Genet 9: 465476.

Takeuchi T, Yamazaki Y, Katohfukui Y, Tsuchiya R, Kondo S, Motoyama J, Higashinakagawa T. 1995. Gene trap capture of a novel mouse gene, jumonji, required for neural-tube formation. Genes Dev 9: 1211-1222.

Takeuchi T, Watanabe Y, Takano-Shimizu T, Kondo S. 2006. Roles of jumonji and jumonji family genes in chromatin regulation and development. Dev Dyn 235: 2449-2459.

Talbert PB, Henikoff S. 2006. Spreading of silent chromatin: Inaction at a distance. Nat Rev Genet 7: 793-803.

Tamaru H, Selker EU. 2001. A histone H3 methyltransferase controls DNA methylation in Neurospora crassa. Nature 414: 277-283.

Tamaru H, Selker EU. 2003. Synthesis of signals for de novo DNA methylation in Neurospora crassa. Mol Cell Biol 23: 2379-2394.

Tamaru H, Zhang $\mathrm{X}$, McMillen D, Singh PB, Nakayama J, Grewal SI, Allis CD, Cheng XD, Selker EU. 2003. Trimethylated lysine 9 of histone $\mathrm{H} 3$ is a mark for DNA methylation in Neurospora crassa. Nat Genet 34: 75-79.

Thon G, Bjerling P, Bunner CM, Verhein-Hansen J. 2002. Expression-state boundaries in the mating-type region of fission yeast. Genetics 161: 611-622.

Trewick SC, McLaughlin PJ, Allshire RC. 2005. Methylation: Lost in hydroxylation? EMBO Rep 6: 315-320.

Trewick SC, Minc E, Antonelli R, Urano T, Allshire RC. 2007. The JmjC domain protein Epel prevents unregulated assembly and disassembly of heterochromatin. EMBO J 26: 4670 4682.

Tschiersch B, Hofmann A, Krauss V, Dorn R, Korge G, Reuter G. 1994. The protein encoded by the Drosophila position-effect variegation suppressor gene SU/VAR)3-9 combines domains of antagonistic regulators of homeotic gene complexes. EMBO J 13: 3822-3831.

Tsukada Y, Fang J, Erdjument-Bromage H, Warren ME, Borchers $\mathrm{CH}$, Tempst P, Zhang Y. 2006. Histone demethylation by a family of JmjC domain-containing proteins. Nature 439: 811-816.

Tsukahara S, Kobayashi A, Kawabe A, Mathieu O, Miura A, Kakutani T. 2009. Bursts of retrotransposition reproduced in Arabidopsis. Nature 461: 423-426.

Ufano S, San-Segundo P, del Rey F, de Aldana CRV. 1999. SWM1, a developmentally regulated gene, is required for spore wall assembly in Saccharomyces cerevisiae. Mol Cell Biol 19: $2118-2129$.
Verdel A, Jia ST, Gerber S, Sugiyama T, Gygi S, Grewal SIS, Moazed D. 2004. RNAi-mediated targeting of heterochromatin by the RITS complex. Science 303: 672-676.

Volpe TA, Kidner C, Hall IM, Teng G, Grewal SIS, Martienssen RA. 2002. Regulation of heterochromatic silencing and histone H3 lysine-9 methylation by RNAi. Science 297: 1833-1837.

Vongs A, Kakutani T, Martienssen RA, Richards EJ. 1993. Arabidopsis-thaliana DNA methylation mutants. Science 260: $1926-1928$.

Wassenegger M. 2000. RNA-directed DNA methylation. Plant Mol Biol 43: 203-220.

Wassenegger M, Heimes S, Riedel L, Sanger HL. 1994. RNAdirected de-novo methylation of genomic sequences in plants. Cell 76: 567-576.

Xie ZX, Johansen LK, Gustafson AM, Kasschau KD, Lellis AD, Zilberman D, Jacobsen SE, Carrington JC. 2004. Genetic and functional diversification of small RNA pathways in plants. PLOS Biol 2: 642-652.

Yamada T, Fischle W, Sugiyama T, Allis CD, Grewal SIS. 2005. The nucleation and maintenance of heterochromatin by a histone deacetylase in fission yeast. Mol Cell 20: 173-185.

Yoon HJ, Feoktistova A, Wolfe BA, Jennings JL, Link AJ, Gould KL. 2002. Proteomics analysis identifies new components of the fission and budding yeast anaphase-promoting complexes. Curr Biol 12: 2048-2054.

Zhang XY, Yazaki J, Sundaresan A, Cokus S, Chan SWL, Chen HM, Henderson IR, Shinn P, Pellegrini M, Jacobsen SE, et al. 2006. Genome-wide high-resolution mapping and functional analysis of DNA methylation in Arabidopsis. Cell 126: 1189-1201.

Zhang K, Mosch K, Fischle W, Grewal SIS. 2008. Roles of the Clr4 methyltransferase complex in nucleation, spreading and maintenance of heterochromatin. Nat Struct Mol Biol 15: 381-388

Zilberman D, Cao XF, Jacobsen SE. 2003. ARGONAUTE4 control of locus-specific siRNA accumulation and DNA and histone methylation. Science 299: 716-719.

Zilberman D, Cao XF, Johansen LK, Xie ZX, Carrington JC, Jacobsen SE. 2004. Role of arabidopsis ARGONAUTE4 in RNA-directed DNA methylation triggered by inverted repeats. Curr Biol 14: 1214-1220.

Zilberman D, Gehring M, Tran RK, Ballinger T, Henikoff S. 2007. Genome-wide analysis of Arabidopsis thaliana DNA methylation uncovers an interdependence between methylation and transcription. Nat Genet 39: 61-69.

Zofall M, Grewal SIS. 2006. Swi6/HP1 recruits a JmjC domain protein to facilitate transcription of heterochromatic repeats. Mol Cell 22: 681-692. 


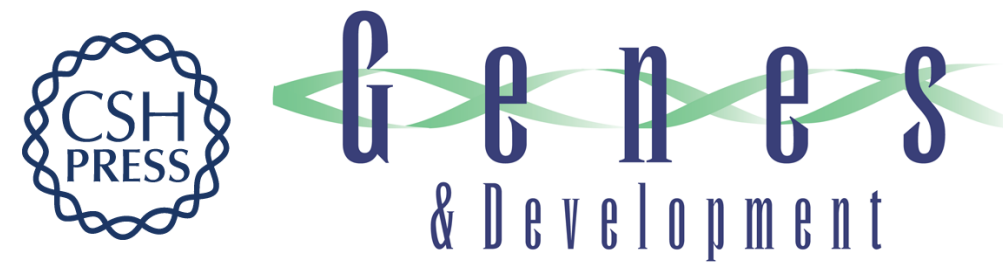

\section{Confining euchromatin/heterochromatin territory: jumonji crosses the line}

Hisashi Tamaru

Genes Dev. 2010, 24:

Access the most recent version at doi:10.1101/gad.1941010

References This article cites 160 articles, 57 of which can be accessed free at: http://genesdev.cshlp.org/content/24/14/1465.full.html\#ref-list-1

License

Email Alerting Receive free email alerts when new articles cite this article - sign up in the box at the top Service right corner of the article or click here.

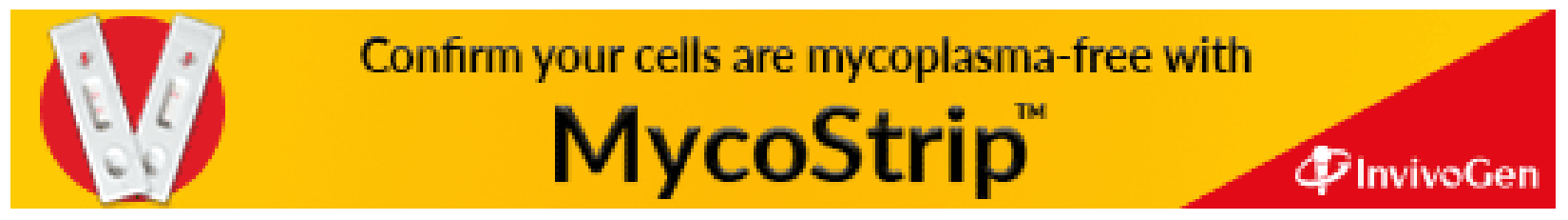

